06

\title{
Структура и оптические свойства нанокомпозитов серебро/полиакрилонитрил
}

\author{
() М.А. Кудряшов, ${ }^{1}$ А.И. Машин,, ${ }^{1}$ А.В. Нежданов, ${ }^{1}$ А.А. Логунов, ${ }^{1}$ Т.А. Грачева, ${ }^{1}$ \\ T.A. Кузьмичева, ${ }^{1}$ G. Chidichimo, ${ }^{2}$ G. De Filpo ${ }^{2}$ \\ ${ }^{1}$ Нижегородский государственный университет им. Н.И. Лобачевского, \\ 603950 Нижний Новгород, Россия \\ ${ }^{2}$ Department of Chemistry, University of Calabria, P. Bucci-15c, \\ 87036 Rende (CS), ITALY \\ e-mail: Kudryashov@phys.unn.ru
}

(Поступило в Редакцию 3 ноября 2015 г.)

\begin{abstract}
Методом рассеяния рентгеновских лучей под малыми углами показано, что в нанокомпозитах серебро/полиакрилонитрил, синтезированных с помощью фотополимеризации смеси нитрата серебра, акрилонитрила, и фотоинициатора, формируются наночастицы серебра размерами от 5 до $11 \mathrm{~nm}$. Изучены оптические свойства нанокомпозитов в зависимости от условий получения. На спектрах поглощения в области длин волн 420-450 nm обнаружен максимум, связанный с поверхностным плазмонным резонансом от наночастиц серебра. Инфракрасные спектры нанокомпозитов подтверждают формирование полиакрилонитрила в процессе фотополимеризации мономера. Образование нановключений металла в полимерной матрице приводит к усилению интенсивности фотолюминесценции и комбинационного рассеяния света полиакрилонитрила.
\end{abstract}

\section{Введение}

Композитные среды на основе наночастиц металла, диспергированных в диэлектрической матрице, могут использоваться в нанофотонике, оптоэлектронике, медицине, в катализе, для хранения информации, а также в поверхностно-усиленном рамановском рассеянии [1-6]. При практическом применении от нанокомпозитов требуется повышенная химическая стойкость и оптическая однородность. Для массового производства таких структур необходим простой метод изготовления при относительно низких температурах. УФ-индуцированная полимеризация мономера при одновременном восстановлении солей или комплексов металлов, растворенных в мономере, хорошо подходит для синтеза металлополимерных нанокомпозитов. Данный способ характеризуется низкими температурными условиями, достаточно высокими скоростями полимеризации и не требует введения дополнительных растворителей и восстановителей.

Повышенный интерес проявляется к оптическим свойствам нанокомпозитов металл/полимер [7,8]. Наличие наночастиц серебра, золота и меди в диэлектрических матрицах дает сильные полосы электронного поглощения в видимой области спектра. К тому же внедрение таких наночастиц в активные среды ведет к существенному усилению в них эффективности оптических процессов, таких как люминесценция, комбинационное рассеяние света и т.д. Физической причиной данного эффекта является существование поверхностных плазмонов на металлических частицах. Взаимодействие электромагнитного поля оптического диапазона с нановключениями металла приводит к специфическим плазмонным резонансам, ответственным за поглощение падающего света и эффект усиления локального поля. Особенности этих явлений определяются геометрией наночастиц, их структурой, а также зависят от оптических свойств матрицы. Исследование структуры нанокомпозитов металл/полимер и ее влияния на оптические свойства являются важной задачей.

В настоящей работе мы приводим результаты исследований структуры методом рассеяния рентгеновских лучей под малыми углами (РМУ), а также оптических свойств методами спектроскопии в видимой и ИК области, фотолюминесценции (ФЛ), комбинационного рассеяния света (КРС) нанокомпозитов серебро/полиакрилонитрил (Ag/ПАН), синтезированных с помощью фотополимеризации при различных концентрациях $\mathrm{AgNO}_{3}$ и фотоинициатора (ФИ) в исходных смесях.

\section{1. Экспериментальная часть}

Нанокомпозитные пленки Ag/ПАН были изготовлены методом фотополимеризации раствора нитрата серебра в акрилонитриле $(\mathrm{AH})$ в присутствии фотоинициатора 2.2-диметокси-1.2-дифенилэтан-1-она. После смешивания мономера ФИ и $\mathrm{AgNO}_{3}$ смесь помещалась между двумя стеклами и облучалась УФ светом с $\lambda=365 \mathrm{~nm} \mathrm{в}$ течение $90 \mathrm{~min}$. При получении варьировала концентрация исходных компонентов. Более подробное описание синтеза нанокомпозитов приведено в работе [9].

Спектры малоуглового рассеяния регистрировались с помощью автоматизированного комплекса для сбора и обработки информации, созданного на базе установки КРМ-1. Коллимация первичного пучка осуществлялась по схеме Кратки, излучение $\mathrm{Cu} K_{\alpha}(\lambda=0.154 \mathrm{~nm})$, монохроматизированное с помощью Ni-фильтра. Данный 
комплекс позволяет регистрировать интенсивность рассеянного излучения $I(s)$ с заданной точностью в заданном интервале углов $\varphi$. Проводя интегральное преобразования кривых $I(s)$ ( $s$ - модуль вектора рассеяния, $\left.s=\frac{2 \pi \sin \varphi}{\lambda}\right)$, можно вычислить ряд структурных характеристик наночастиц: средний размер $R$, распределение по размерам $P(R)$ и др. [10].

Поглощение нанокомпозитных пленок было получено из спектров пропускания, измеренных на спектрофотометре Cary 5000 в диапазоне 300-800 nm с шагом $1 \mathrm{~nm}$ и временем накопления $0.1 \mathrm{~s}$. Комбинационное рассеяние и фотолюминесценция снимались на комплексе рамановской спектроскопии NTEGRA Spectra производства компании NT-MDT (г.Зеленоград). Возбуждение осуществлялось лазерами с длинами волн 473 и $632.8 \mathrm{~nm}$ для ФЛ и КРС соответственно. Излучение фокусировалось 20х объективом с апертурой 0.95. Мощность несфокусированного лазерного излучения, измеряемая с помощью кремниевого фотодетектора 11PD100Si (Standa Ltd), составляла 0.1-5 mW. Спектры КРС и ФЛ образцов были получены в схеме на отражение в интервале $4000-400 \mathrm{~cm}^{-1}$ с шагом $6 \mathrm{~cm}^{-1}$ и $474-814 \mathrm{~nm}$ с шагом $0.3 \mathrm{~nm}$ соответственно. ИК спектры на пропускание в диапазоне $4000-400 \mathrm{~cm}^{-1}$ с разрешением $4 \mathrm{~cm}^{-1}$ снимались на ИК фурье спектрометре Spectrum BX II. Bсе спектры были получены при комнатной температуре.

\section{2. Результаты и их обсуждение}

Нанокомпозитные пленки $\mathrm{Ag} /$ ПАН, полученные при различном соотношении исходных компонент, дают достаточно интенсивное рассеяние рентгеновских лучей в область малых углов, обусловленное наночастицами серебра, сформировавшимися в полимерной матрице. Характерные угловые зависимости $I(s)$ в координатах $\lg (I)$ от $\lg (s)$ приведены на рис. 1, $a$. Как свидетельствуют результаты вычислений, нановключения имеют форму, близкую к сферической (фактор формы меньше 1), и представляют собой полидисперсную систему с достаточно узким распределением по размерам $P(R)$, лежащем в интервале примерно 5-11 nm (примеры кривых $P(R)$ показаны на рис. $1, b)$. В зависимости от условий синтеза меняется положение максимума и форма кривых $P(R)$. Установлено, что с ростом содержания $\mathrm{AgNO}_{3}$ в исходной смеси распределения по размерам показывают увеличение среднего размера наночастиц. Эти данные согласуются с полученными ранее результатами ПЭМ [9], где обнаружена аналогичная зависимость. Некоторые отличия в значениях $R$ могут быть связаны с тем, что в ПЭМ средний размер определяется по дискретным выборкам, а в методе РМУ получают интегральную информацию, усредненную по облучаемому объему.

На рис. 2 представлены спектры поглощения в видимом диапазоне от композитных пленок. На спектрах
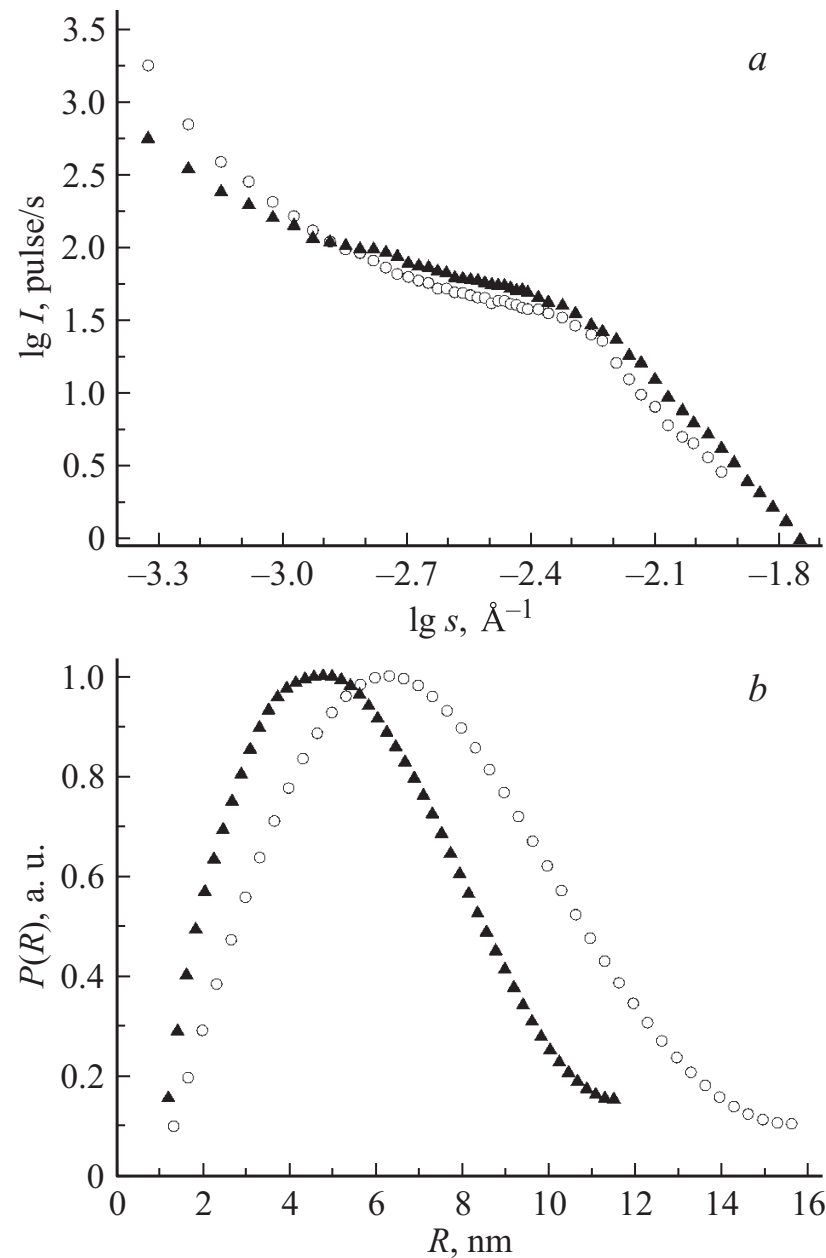

Рис. 1. Кривые малоуглового рассеяния $(a)$ и распределения частиц по размерам $(b)$ нанокомпозитов $\mathrm{Ag} /$ ПАН, полученных при 5 (ム) и 25 (о) wt.\% $\mathrm{AgNO}_{3}$. Содержание ФИ 15 wt\%.

отчетливо виден максимум в области $420-450 \mathrm{~nm}$, который принято связывать с поверхностным плазмонным резонансом от наночастиц серебра, имеющих сферическую форму [11]. Относительно узкие и симметричные полосы плазмонного резонанса свидетельствуют об однородном распределении частиц в полимере и маленьком разбросе по размерам. При повышении концентрации $\mathrm{AgNO}_{3}$ в исходной смеси на спектрах наблюдается красный сдвиг полосы поглощения (рис. 2,a), указывая на увеличение размера нановключений в полимерной матрице. С возрастанием содержания ФИ в исходной смеси обнаруживается сильное увеличение интенсивности максимума (рис. 2, $b$ ), что свидетельствует о росте количества наночастиц в полимере, дающих общий вклад в поверхностный плазмонный резонанс. При этом положение пика смещается в коротковолновую область, что говорит об уменьшении размера наночастиц $\mathrm{Ag}$, диспергированных в полиакрилонитриле. Полученные спектры поглощения хорошо согласуется с кривыми РМУ и данными ПЭМ [9]. 

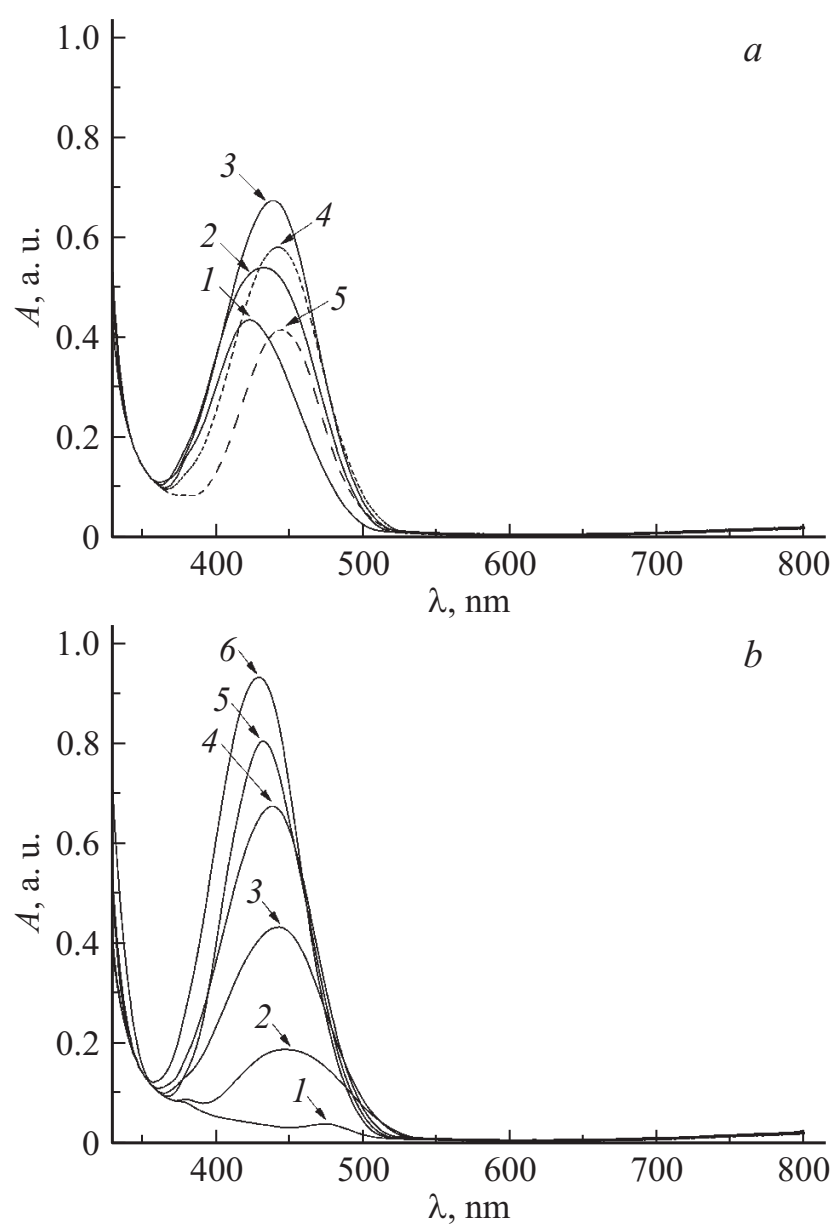

Pис. 2. Спектры поглощения нанокомпозитов $\mathrm{Ag} /$ ПАН, полученных при $15 \mathrm{wt} . \%$ ФИ с разной концентрацией нитрата серебра (a), wt.\%: $1-2,2-5,3-10,4-15,5-20$ и при $10 \mathrm{wt} \% \mathrm{AgNO}_{3}$ с разной концентрацией ФИ (b), wt.\%: $1-2,2-5,3-10,4-15,5-20,6-25$.

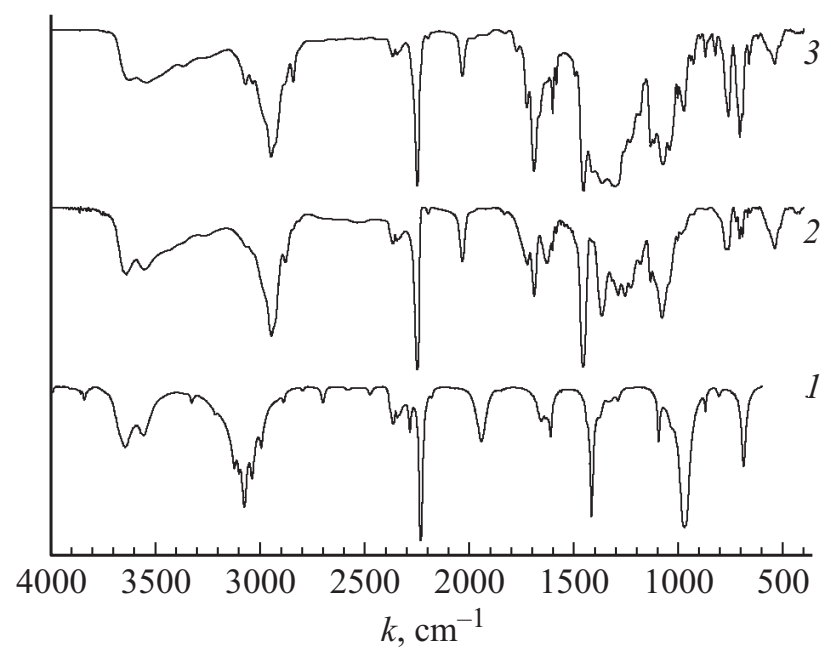

Рис. 3. ИК спектры АН (1), ПАН (2) и нанокомпози-

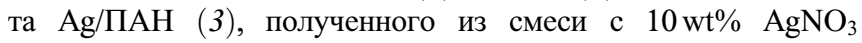
и 15 wt.\% ФИ.
На рис. 3 показаны ИК спектры пропускания чистого $\mathrm{AH}$, ПАН, полученного фотополимеризацией, и нанокомпозита $\mathrm{Ag} / П А Н$, полученного при $10 \mathrm{wt} \% \mathrm{AgNO}_{3}$ и 15 wt.\% ФИ в исходной смеси. Появление на спектре нанокомпозитов полос поглощения при $3000-2900 \mathrm{~cm}^{-1}$ и $1454 \mathrm{~cm}^{-1}$ (валентные и деформационные колебания связи СН соответственно), а также смещение минимумов от связи $C \equiv N$ с 2230 к $2245 \mathrm{~cm}^{-1}$ указывает на полимеризацию АН. Кроме минимумов от ПАН наблюдаются полосы поглощения в области 1435-1260 и $820 \mathrm{~cm}^{-1}$ от связи $\mathrm{NO}_{2}$. Данные полосы возникают вследствие диссоциации $\mathrm{AgNO}_{3}$ в АН при изготовлении исходной смеси.

Полосу поглощения при $2030 \mathrm{~cm}^{-1}$ в работе [12] объясняют взаимодействием ионов серебра с группами - $\mathrm{CN}$ полиакрилонитрила $(\mathrm{Ag}-\mathrm{CN})$. Однако в нашем случае она проявляется как в нанокомпозитах $\mathrm{Ag} /$ ПАН, так и в ПАН без наночастиц серебра. Поэтому уместно отнести поглощение в этой области к $\mathrm{C}=\mathrm{N}$ связи кетениминных групп, образование которых возможно в нашей системе [13].

В ИК спектрах нанокомпозитов отдельно следует выделить полосу поглощения при $970 \mathrm{~cm}^{-1}$, которая соответствует двойной связи $\mathrm{C}=\mathrm{C}$ в акрилонитриле. В данном случае она характеризует присутствие не вступившего в реакцию полимеризации мономера в нанокомпозитах Ag/ПАН, который играет роль пластификатора синтезируемых пленок. Интенсивность этой полосы сильно зависит от концентрации $\mathrm{AgNO}_{3}$ и ФИ в исходной смеси (рис. 4). С увеличением содержания нитрата серебра в смеси глубина минимума на спектре растет. Напротив, с ростом концентрации ФИ полоса поглощения уменьшается. Таким образом, повышение содержания $\mathrm{AgNO}_{3}$ в исходной смеси „препятствует“ полимеризации $\mathrm{AH}$, и нанокомпозит получается более пластичным, а при увеличении концентрации ФИ мы получаем более хрупкую пленку. Следовательно, при варьировании содержания $\mathrm{AgNO}_{3}$ и ФИ в исходной смеси изменяется вязкость полимерной матрицы, а значит и коэффициент диффузии серебра в ней. Этим мы контролируем размер и плотность наночастиц серебра. Данный эффект наблюдался нами в ранних исследова-

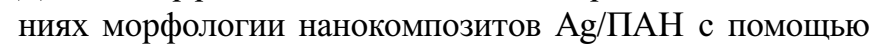
ПЭМ [9].

При детальном изучении полосы поглощения от связи $\mathrm{C} \equiv \mathrm{N}$ при $2245 \mathrm{~cm}^{-1}$ выявлено, что ее форма зависит от содержания $\mathrm{AgNO}_{3}$ в исходной смеси. А именно с увеличением концентрации нитрата серебра со стороны высоких волновых чисел у этой полосы появляются побочные минимумы. Данный факт объясняется возможным образованием комплекса нитрата серебра с $\mathrm{CN}$-связью мономера и полимера [14], что, вероятно, препятствует формированию наночастиц серебра.

Исследование ФЛ нанокомпозитов $\mathrm{Ag} /$ ПАН показало наличие широкого максимума в области $560 \mathrm{~nm}$, интенсивность которого сильно зависит от концентрации компонентов в исходной смеси. Согласно рабо- 
те [15], данный максимум относится к „универсальной“ флуоресценции ПАН, подверженного деструкции. На рис. 5, $a$ показаны спектры фотолюминесценции
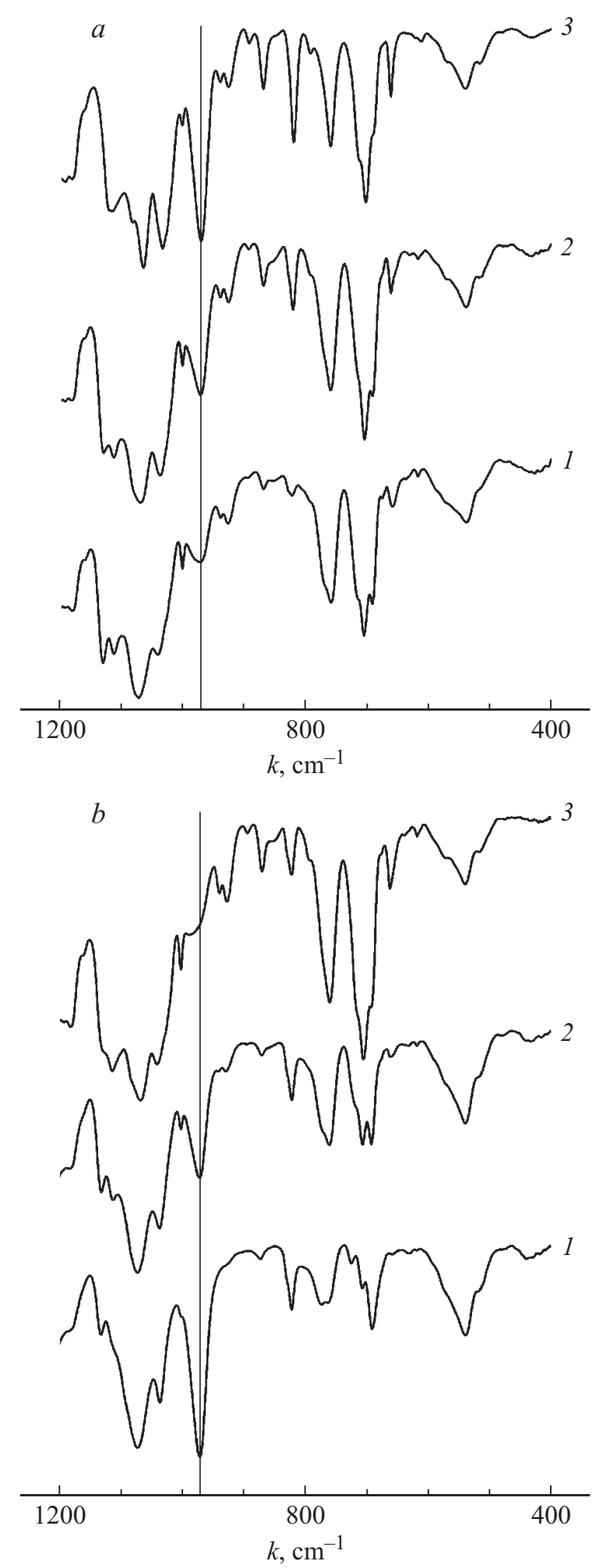

Рис. 4. ИК спектры нанокомпозитов $\mathrm{Ag} / П А Н$, полученных при 15 wt.\% ФИ с разной концентрацией $\mathrm{AgNO}_{3}(a)$, wt.\%: $1-5,2-15,3-25$ и при 10 wt. $\% \mathrm{AgNO}_{3}$ с разной концентрацией ФИ $(b)$, wt.\%: $1-2,2-5,3-20$.
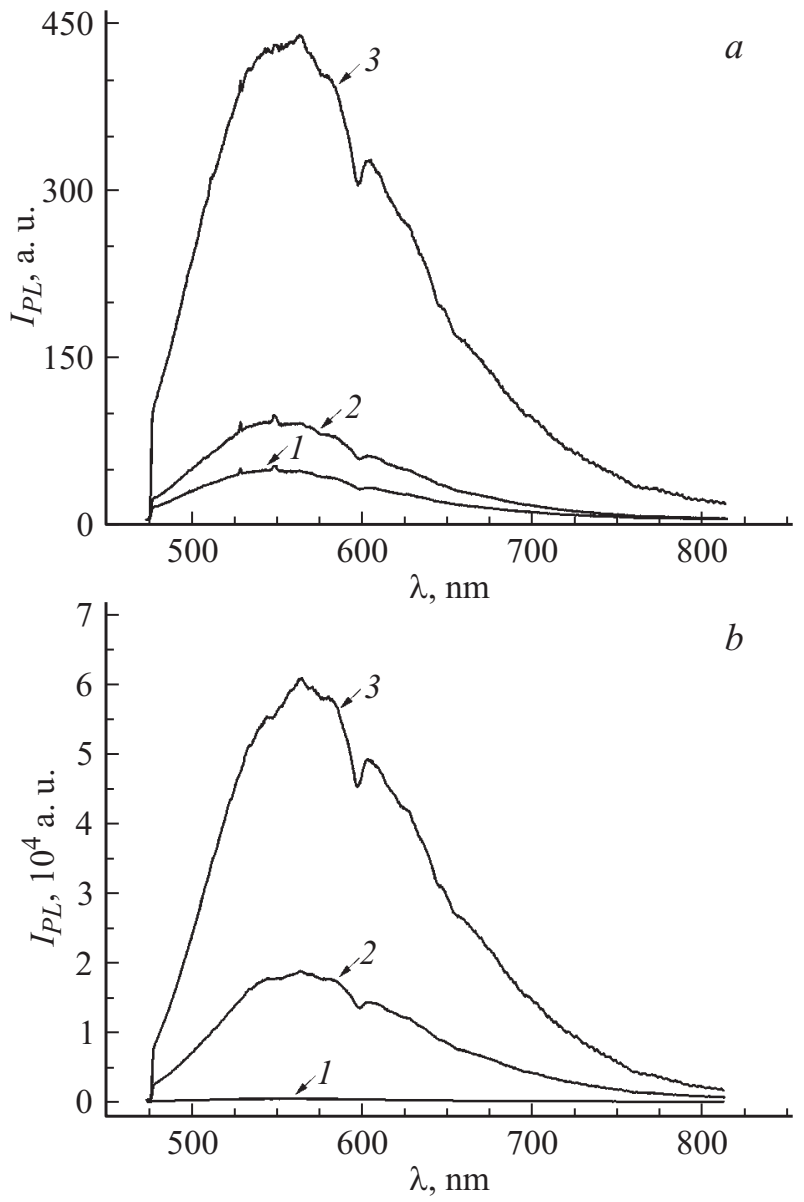

Рис. 5. Спектры ФЛ ПАН (a) при разной концентрации ФИ, wt.\%: $1-0.5,2-2,3-15$ и нанокомпозитов $\mathrm{Ag} /$ ПАН $(b)$ при $15 \mathrm{wt} . \%$ ФИ с разной концентрацией $\mathrm{AgNO}_{3}$, wt.\%: $1-0,2-2,3-25$.

ПАН, полученного фотополимеризацией при различном содержании фотоинициатора в мономере. С увеличением концентрации ФИ интенсивность ФЛ возрастает. Добавление в исходную смесь $2 \mathrm{wt} . \% \mathrm{AgNO}_{3}$ приводит к резкому скачку (примерно в 41 раз) интенсивности ФЛ в получаемых образцах (рис. 5, $b$ ), как результат формирования в полимерной матрице нановключений серебра. Как известно [16], внедрение наночастиц металла в активную среду ведет к существенному усилению эффективности люминесценции вследствие существования поверхностных плазмонов. С дальнейшим увеличением концентрации $\mathrm{AgNO}_{3}$ интенсивность ФЛ возрастает из-за роста объемной доли серебра в полиакрилонитриле (центров локального усиления поля).

Измерение спектров КРС осуществлялось при возбуждении лазером на длине волны $632.8 \mathrm{~nm}$ с целью избежать паразитного влияния ФЛ. На рис. 6, $a$ представлены спектры КРС от ПАН, полученного при 0.5 и 15 wt.\% фотоинициатора в исходной смеси. На спектрах три характерных пика при 3000-2900, 2244 и $1455 \mathrm{~cm}^{-1}$, 

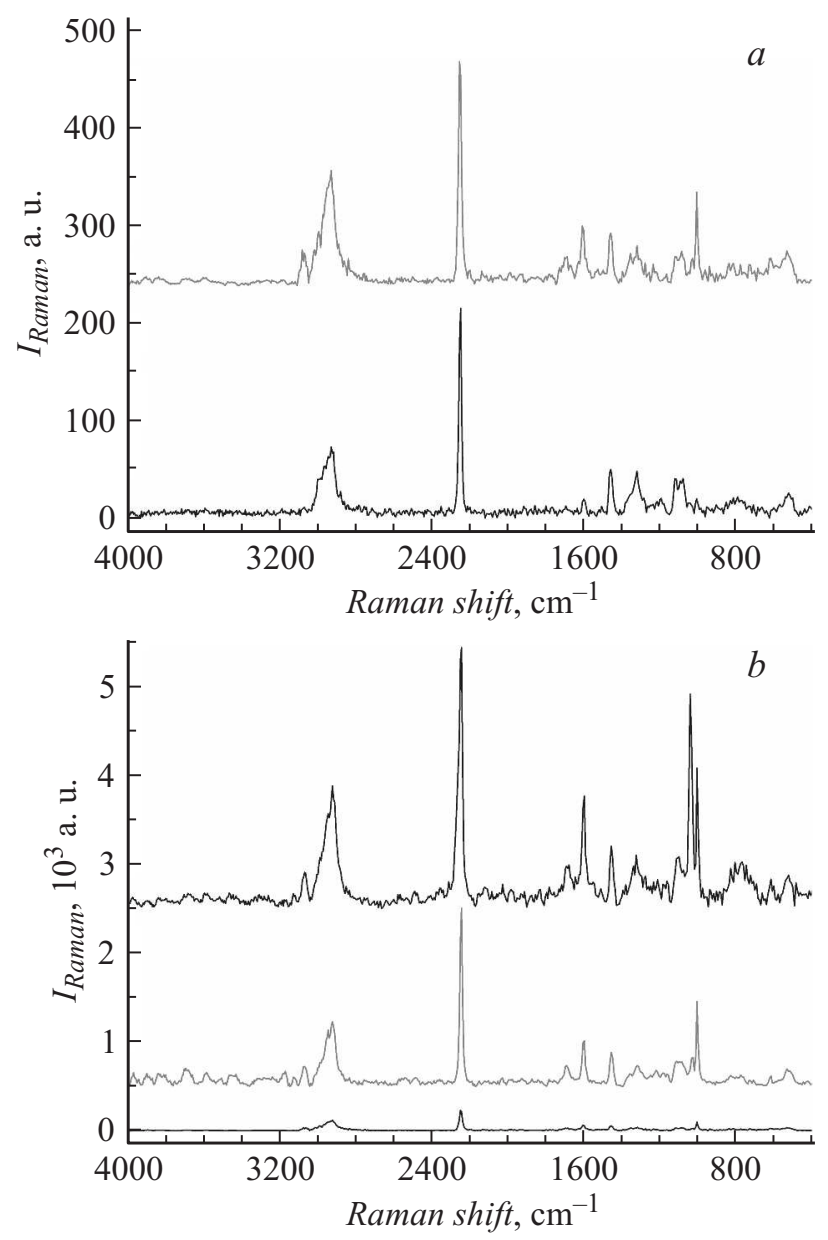

Рис. 6. Спектры КРС ПАН $(a)$ при разной концентрации ФИ, wt.\%: $1-0.5,2-15$ и нанокомпозитов $\mathrm{Ag} / П А Н ~(b)$ при 15 wt.\% ФИ с разной концентрацией $\mathrm{AgNO}_{3}$, wt.\%: 1 - 0 , $2-2,3-25$.

принадлежащие валентным колебаниям связи СН, валентным колебаниям связи $\mathrm{C} \equiv \mathrm{N}$ и деформационным колебаниям связи СН соответственно. Положения данных максимумов хорошо согласуется с результатами ИК спектроскопии. Кроме того, на спектрах наблюдаются пики при 1003, 1597, 1690 и $3070 \mathrm{~cm}^{-1}$, которые слабо проявляются при $0.5 \mathrm{wt} \%$ фотоинициатора в исходной смеси и возрастают с его увеличением. Можно предположить, что эти пики связаны с присутствием продуктов распада ФИ.

В присутствии наночастиц серебра в полимере (рис. 6, $b$ ) происходит резкое увеличение интенсивности спектров (примерно в 8 раз). Повышение интенсивности спектров коррелирует с ростом содержания $\mathrm{AgNO}_{3}$ в исходной смеси, а следовательно, и с увеличением объемной доли нановключений в полимерной матрице [9]. Наблюдаемый эффект можно связать с явлением поверхностно-усиленного рамановского рассеяния (гигантского комбинационного рассеяния света). $\mathrm{C}$ ростом концентрации $\mathrm{AgNO}_{3}$ интенсивность КРС возрастает, как и интенсивность ФЛ. Не столь суще- ственное увеличение интенсивности спектров по сравнению с литературными данными [17], вероятно, связано с небольшой объемной долей наночастиц серебра в полимере (до 1\%) [9]. Так же на спектрах КРС нанокомпозитов $\mathrm{Ag} /$ ПАН появляется пик при $1039 \mathrm{~cm}^{-1}$ от связи $\mathrm{NO}_{2}$, вследствие диссоциации AgNO3 в АН при изготовлении исходной смеси, как и в случае ИК спектров.

\section{3. Заключение}

Исследование нанокомпозитных пленок методом РМУ подтверждает формирование в полимерной матрице наночастиц серебра сферической формы. Спектры поглощения в видимом диапазоне нанокомпозитов $\mathrm{Ag} /$ ПАН показали наличие характерного максимума в области 420-450 nm, связанного с поверхностным плазмонным резонансом от наночастиц серебра. Положение данного максимума хорошо согласуется с результатами ПЭМ. ИК спектры от нанокомпозитов указывают на образование полиакрилонитрила в процессе полимеризации мономера. Однако в нанокомпозитах присутствует не вступивший в реакцию полимеризации акрилонитрил, играющий роль пластификатора. Выявленные пики на спектрах КРС хорошо согласуются с данными ИК спектроскопии. Обнаруженное усиление интенсивности фотолюминесценции и комбинационного рассеяния света в 41 и 8 раз соответственно связано с существованием поверхностных плазмонов в наночастицах серебра.

Работа выполнена в рамках базовой части государственного задания в сфере научной деятельности по заданию № 2014/134 (проект 1958) на 2014-2016 гг.

\section{Список литературы}

[1] Shenhar R., Norsten T.B., Rotello V.M. // Adv. Mater. 2005. Vol. 17. N 6. P. 657-669.

[2] Kamat P.V. // J. Phys. Chem. B. 2002. Vol. 106. N 32. P. 7729 7744.

[3] Porel S., Ramakrishna D., Hariprasad E., Dutta Gupta A., Radhakrishnan T.P. // Curr. Sci. 2011. Vol. 101. N 7. P. $927-$ 934.

[4] Hariprasad E., Radhakrishnan T.P. // Chem. Eur. J. 2010. Vol. 16. N 48. P. 14378-14 384.

[5] Kang M., Chung K., Baeg K.-J., Kim D.H., Kim C. // Appl. Phys. Lett. 2015. Vol. 106. N 4. P. 043302.

[6] Tao A., Kim F., Hess C., Goldberger J., He R., Sun Y., Xia Y., Yang P. // Nano Lett. 2003. Vol. 3. N 9. P 1229-1233.

[7] Liu X., Matsumura K., Tomita Y., Yasui K., Kojima K., Chikama K. // J. Appl. Phys. 2010. Vol. 108. N 7. P. 073102.

[8] Karthikeyan B. / J. Appl. Phys. 2010. Vol. 108. N 8. P. 084311.

[9] Кудряшов М.А., Машин А.И., Тюрин А.С., Федосов А.Е., Chidichimo G., De Filpo G. // ЖТФ. 2011. Т. 81. Вып. 1. C. $95-100$. 
[10] Саломатина Е.В., Кузьмичева Т.А., Мочалова А.Е., Грачева Т.А., Смирнова Л.А., Бобров А.А., Бугрова М.Л. // Российские нанотехнологии. 2013. Т. 8. № 11-12. С. 53-57.

[11] Machulek J.A., De Oliveira H.P.M., Gehlen M.H. // Photochem. Photobiol. Sci. 2003. Vol. 2. N 9. P. 921-925.

[12] Liu H., Ge X., Ni Y., Ye Q., Zhang Z. // Radiat. Phys. Chem. 2001. Vol. 61. N 1. P. 89-91.

[13] Инфракрасная спектроскопия полимеров / Под ред. Э.Ф. Олейника. М.: Химия, 1976. 472 с.

[14] Janz G.J., Tait M.J., Meier J. // J. Phys. Chem. 1967. Vol. 71. N 4. P. $963-968$.

[15] Гачковский В.Ф. // Высокомолек. соед. 1970. Т. 12. № 6. C. 411-413.

[16] Peng J., Xu X., Tian Y., Wang J., Tang F., Li L. // Appl. Phys. Lett. 2014. Vol. 105. N 17. P. 173301.

[17] Gopinath A., Boriskina S.V., Reinhard B.M., Negro L.D. // Opt. Express. 2009. Vol. 17. N 5. P. 3741-3753. 